\title{
Epidemiology and impact on liver function of HepB, HepC, and HIV Infections in Multitransfused Thalassemic Patients in a Tertiary care Hospital in West Bengal, India
}

\author{
Arnab Biswas ${ }^{1}$, Birendra Nath Roy ${ }^{2}$, Kaberi Basu $^{3}$ \\ ${ }^{I}$ Assistant professor, Department of pediatrics, NRSMCH, Kolkata, WB, India \\ ${ }^{2}$ Professor, Department of pediatrics, NRSMCH, Kolkata, WB, India \\ ${ }^{3}$ Ex Professor, Department of pediatrics, Medical college, Kolkata, WB, India
}

\begin{abstract}
To know the prevalence of $H B V, H C V$, and HIV infection in multitransfused thalassemic children \& Correlation between these infections \& liver function status this Cross-sectional Observational Study, was conducted in a tertiary care hospital Medical College, Kolkata. One hundred patients(61 males and 39 females) from eight districts of southern West Benga,India with beta-thalassemia major with more than 10 blood transfusions, were tested for HBsAg, anti-HCV antibodies \& anti-HIV antibodies along with liver function test. It was found that $H C V(25 \%) \& H I V(15 \%)$ were major transfusion associated infections. Liver function was abnormal in patients with $H C V$ and HIV infection with $P<0.001 \& P<0.05$ respectively. $H C V \& H I V$ are major transfusion associated infections, in multitransfused thalassemics, thus emphasizing the need for better pretransfusion screening of blood and vaccination against $H B V$ if possible.
\end{abstract}

Keywords: Beta thalassemia major, Hepatitis B Virus, Hepatitis C Virus, Human Immuno Deficiency Virus.

\section{Introduction}

Regular blood transfusion in patients with thalassemia, has improved their overall survival, but carries a definite risk of acquisition of blood-borne viral infections, especially viral hepatitis. Nowadays, vaccination against hepatitis B has efficiently been able to restrict the transmission of hepatitis B virus (HBV) infection. However, post-transfusion transmission of hepatitis $\mathrm{C}$ virus (HCV) has still remained a major health concern in thalassemic patients. In addition, since marked liver iron overload, which is often inevitable in patients on regular blood transfusion, and $\mathrm{HCV}$ infection have been shown to have a potentiating effect on hepatic fibrogenesis in thalassemic patients. ${ }^{[1]}$ Chronic hepatitis $\mathrm{C}$ has been indicated as a progressive disease that dramatically increases the morbidity and mortality rates among these patients due to liver failure or hepatocellular carcinoma ${ }^{[2]}$ The prevalence of $\mathrm{HCV}$ infection among thalassemic patients has been reported to be up to $60 \%$ in Italy, ${ }^{[3]}$ although the compulsory screening of donated bloods has decreased the incidence of both posttransfusion $\mathrm{HBV}$ and $\mathrm{HCV}$ infections. ${ }^{[4]} \mathrm{A}$ study in Thailand showed that the patients with anti-HCV antibodies had significantly abnormal liver function test. However, there were also significant correlations between iron status as indicated by transferrin saturation or serum ferritin levels and SGOT, SGPT, and 3glutamyltransferase (GGT) levels ${ }^{[5]} \mathrm{We}$ conducted this study to provide a comprehensive data bank on the epidemiology of HBV, HCV, and human immunodeficiency virus (HIV) infections in patients with $\beta$ thalassemia in west Bengal \& their effects on liver function have also been determined.

\section{Materials and Methods}

This Cross-sectional Observational Study was carried out in Inpatient pediatric ward in a tertiary care hospital, Medical College, Kolkata for one year. One hundred patients with $\beta$-thalassemia major up to 12 years of age from eight districts of West Bengal including Kolkata(n=15), Hoogly(n=17), Howrah(n=23), 24Parganas- $\mathrm{N}(\mathrm{n}=10), \quad$ 24Parganas- $\mathrm{S}(\mathrm{n}=10), \quad$ PaschimMidnipur $(\mathrm{n}=15), \quad$ PurbaMedinipur $(\mathrm{n}=7), \quad$ Purulia $(\mathrm{n}=3)$ admitted in our in-patient pediatric ward, for blood transfusion were enrolled in this study. All enrolled patients had history of more than 10 blood transfusions. Patients with a history of less than 10 blood transfusions, doubtful diagnosis and unwilling patients or parents were excluded from our study. Initial data including confirmation of diagnosis by hemoglobin electrophoresis, transfusion history and previous medical history including vaccination, splenectomy etc was obtained by reviewing medical records and interviews. Thereafter, venous blood samples were obtained from each patient before blood transfusion and were sent for standard ELISA test for HIV, Surface antigen (HbsAg) for HBV and IgM Anti HCV antibody for HCV along with Liver Function Test (LFT).

The study protocol was approved by our institutional review board and informed written consent was taken from parents of each patient involved. 
Results are expressed as mean \pm standard deviation (SD). Comparison between two groups was made using the Student's $t$ test for continuous variables. A $P$ value $<0.05$ was considered statistically significant. All statistical analyses were performed using SPSS software for Windows (version 10.0; SPSS Inc. Chicago, IL, USA).

\section{Results and Analysis}

Of the total 100 multitransfused children included in the study, 61 were males and 39 were females. Maximum cases of seropositivity were found among the patients of Howrah district followed by Kolkata, Paschim Medinipur, Hoogly and Purulia respectively. Of the total 100 cases, 15 cases were positive for HIV, 25 cases were positive for HCV and 5 cases for HBV. 7 cases were positive for both HIV and HCV and 3 cases were positive for HIV, HCV and HBV. (Table I)

Table I Prevalence of viral seromarkers in the study population.

\begin{tabular}{|l|l|l|}
\hline Viral markers & Total No. & No. of positive cases \\
\hline HCVAb & 100 & 25 \\
\hline HBsAg & 100 & 05 \\
\hline HIVAb & 100 & 15 \\
\hline HCVAb + HIVAb & 100 & 07 \\
\hline HCVAb+HIVAb+HBsAg & 100 & 03 \\
\hline
\end{tabular}

Maximum number of children have been receiving transfusion from 6 to 8 years (28 children) and the maximum prevalence of infection ( 20 children)were also noted in this group. Only 10 children have been receiving transfusion for less than 2 years and of them only 1 case of seropositivity was noted. There is an increasing tendency of infection till 6 to 8 years duration of transfusion.

There was no significant relationship between the presence of anti-HCV antibodies and the number and frequency of blood transfusions. Patients with anti-HCV antibodies, anti-HIV antibodies had significantly abnormal liver functions, such as higher levels of serum aspartate aminotransferase (SGOT) and alanine aminotransferase (SGPT) with $P<0.001 \& P<0.005$ respectively, and lower levels of serum albumin compared with patients without anti-HCV \&/or anti-HIV antibodies.(Table II)

TABLE II Liver function changes in HIV and HCV infection

\begin{tabular}{|c|c|c|c|c|c|c|}
\hline & \multicolumn{2}{|c|}{ SGOT } & \multicolumn{4}{|c|}{ SGPT } \\
\hline INFE-CTIONS & Reactive & $\begin{array}{l}\text { Non- } \\
\text { Reactive }\end{array}$ & $P$ value & Reactive & $\begin{array}{l}\text { Non- } \\
\text { Reactive }\end{array}$ & $\mathrm{P}$ value \\
\hline HIV & $\begin{array}{l}X 1=111 \\
S 1=67.50 \\
\mathrm{~N} 1=25\end{array}$ & $\begin{array}{l}X 2=77 \\
\text { S2 }=37.48 \\
\text { N2 }=45\end{array}$ & $<0.05$ & $\begin{array}{l}X 1=89.77 \\
S 1=61.58 \\
N 1=25\end{array}$ & $\begin{array}{l}\mathrm{X} 2=64.03 \\
\mathrm{~S} 2=30.42 \\
\mathrm{~N} 2=45\end{array}$ & $<0.05$ \\
\hline $\mathrm{HCV}$ & $\begin{array}{l}\mathrm{X} 1=120.07 \\
\mathrm{~S} 1=36.93 \\
\mathrm{~N} 1=35\end{array}$ & $\begin{array}{l}\mathrm{X} 2=67.23 \\
\mathrm{~S} 2=42.25 \\
\mathrm{~N} 2=45\end{array}$ & $<0.001$ & $\begin{array}{l}X 1=99.61 \\
S 1=31.11 \\
N 1=35\end{array}$ & $\begin{array}{l}X 2=55.15 \\
\text { S2 }=36.33 \\
\mathrm{~N} 2=45\end{array}$ & $<0.001$ \\
\hline
\end{tabular}

$\mathrm{P}=<0.05$ is statistically significant.

\section{Discussion}

We carried out this study on children with $\beta$-thalassemia major from various districts of West Bengal to provide a comprehensive epidemiologic data on $\mathrm{HBV}, \mathrm{HCV}$, and $\mathrm{HIV}$ infections among thalassemic population of West Bengal. In this study, we revealed that $35 \%$ of $\beta$-thalassemia major patients were $\mathrm{HCV}$ infected, which is very much higher than the prevalence among general population in Eastern India $(1.85 \%) .{ }^{[6]}$ Similarly, a high prevalence of HIV infection was noted $(25 \%)$, which is pretty higher than the prevalence in thalassemic patients in India $(8.9 \%)$ was reported previously. ${ }^{[7]}$ Five percent of our patients were HBsAg positive, which is little higher than the value reported from the general population (2.97\%) of Eastern India. ${ }^{[8]}$

High seroprevalence of these infections may be due to lack of anti-HCV screening of blood products in the blood banks in Government and private sector, proper screening in the blood banks using Third and Fourth generation ELISA test is not done correctly or may be the kits labelled as ELISA are at fault. Professional donors are also on the increase than voluntary donors.

Patients with anti-HCV antibodies and anti-HIV antibodies had significantly abnormal liver functions and there were also significant correlations between iron status as indicated by serum ferritin levels and SGOT, SGPT levels. The findings suggest that HCV, HIV and iron overload are the main causes of abnormal liver function in these patients with thalassemia. 
HCV \& HIV infections are major transfusion associated problems in multitransfusedthalassemics. For that, there is a need for better pretransfusion screening of blood, vaccination against HBV in such children and the treatment of both problems (iron overload \& viral hepatitis), if coexisting in patients with thalassemia, is required to prevent progression to chronic liver disease.

\section{References}

[1]. Ardalan FA, Osquei MRF, Toosi MN, Irvanloo G. Synergic effect of chronic hepatitis C infection and betathalassemia major with marked hepatic iron overload on liver fibrosis: a retrospective cross-sectional study. BMCGastroenterology.2004;4:17.

[2]. Tong MJ, El-Farra NS, Reikes AR, Co RL. Clinical outcomes after transfusion- associated hepatitis C. N Engl J Med. 1995;vol332; no 22; p1463 - 1466.

[3]. Angelucci E. Antibodies to hepatitis C virus in thalassemia. Haematologica.1994; 79, Issue 4,353 - 355

[4]. Mele A, Stroffolini T, Catapano R, Palumbo F, Moiraghi A, Novaco F. Incidence of transfusion-associated B and non-A, and nonB hepatitis in Italy. Br Med J. 1995;311:846 - 847.

[5]. Wanachiwanawin W, Luengrojanakul P, Sirangkapracha P, Leowattana W, Fucharoen S. Prevalence \& clinical Significance of Hepatitis C Virus Infection in Thai Patients with Thalassemia. International Journal of Hematology. 2003; Vol 78, Number 4, Pages :374-378

[6]. AbhijitChowdhury, AmalSantra, SusmitaChaudhuri, Gopal Krishna Dhali, DebendraNathGuhaMazumder, SatyaGopalMaity, et alHepatitis $\mathrm{C}$ virus infection in the general population: A community-based study in West Bengal, India. Hepatology: 2003; Volume 37, Issue 4, Pages 802 - 809.

[7]. Sen S, Mishra NM, Giri T, Pande I, Khare SD, Kumar A, et al. Acquired immunodeficiency syndrome (AIDS) in multitransfused children with thalassemia. IndianPediatr.1993; 30:455 - 460.

[8]. Chowdhury A, Santra A, Chakravorty R, Banerji A, Pal S, Dhali GK, et al. Community-based epidemiology of hepatitis B virus infection in West Bengal, India: Prevalence of hepatitis B e antigen-negative infection and associated viral variants. $J$ GastroenterolHepatol 2005; 20: 1712-20. 